

\section{De olho no}

\section{futuro: a 4}

Bonforôncla

Pacional

do Bî̄ncia,

Toenologita e

Inovação 


\section{RESUMO}

A $4^{\text {a }}$ Conferência Nacional de Ciência, Tecnologia e Inovação para um Desenvolvimento Sustentável foi realizada no período de 26 a 28 de maio de 2010. Precedida de conferências regionais, estaduais e municipais, e de seminários que aprofundaram alguns dos grandes temas abordados pela Conferência, mobilizou milhares de pessoas. O Livro Azul da $4^{\text {a CNCTI, }}$ acompanhado de um volume que contém as recomendações das conferências regionais e estaduais, resume as principais propostas para a próxima década. Este artigo destaca os grandes desafios debatidos na Conferência e a agenda para o futuro que resultou desses debates.

Palavras-chave: desenvolvimento sustentável, política de Estado, região amazônica.

\section{ABSTRACT}

The $4^{\text {th }} \mathrm{CNCTI}$-National Conference on Science, Technology and Innovation for a Sustainable Development - was held on May 26-28, 2010. Preceded with regional, state-wide and city-wide conferences, and of seminars which deepened some of the major themes covered by the Conference, it gathered thousands of people. The Blue Book of the $4^{\text {th }}$ CNCTI followed by a volume containing the recommendations from the regional and state-wide conferences, sums up the main proposals for the next decade. This article highlights the main challenges debated at the Conference and the agenda for the future which resulted from those debates.

Keywords: sustainable development, state policy, Amazon region. 


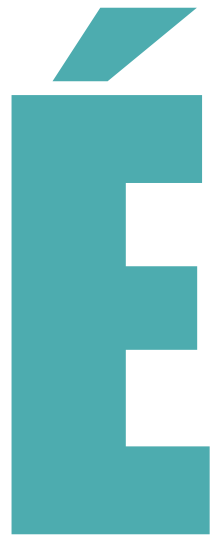

difícil imaginar três palavras mais associadas ao futuro do que ciência, tecnologia e inovação. Por isso mesmo, a 4 ${ }^{\text {a }}$ Conferência Nacional de Ciência, Tecnologia e Inovação para um DesenvolvimentoSustentável (4ª CNCTI) olhou para o futuro, visando uma política de Estado para a próxima década, um projeto de desenvolvimento sustentável nos âmbitos da natureza e da sociedade.

A conferência não se resumiu ao período de 26 a 28 de maio, quando quatro mil pessoas acompanharam presencialmente os debates em Brasília, acessados, além disso, em tempo real, por mais de quarenta mil internautas. Foram meses de intensa participação de vários setores da sociedade brasileira, através de seminários preparatórios, reuniões regionais, estaduais e municipais, encontros com segmentos empresariais e governamentais, com entidades representativas da comunidade acadêmica, com movimentos sociais.

E a mobilização continuou após o evento em Brasília. Os relatores das diversas sessões da Conferência Nacional participaram de uma reunião para levantamento das propostas, e consultas sobre textos preliminares dos documentos da $4^{\text {a }}$ CNCTI - o Livro Azul, que sintetiza os grandes temas debatidos, e a Consolidação das Propostas das Conferências Nacional, Regionais, Estaduais e do Fórum Municipal de Ciênciae Tecnologia - foram feitas junto ao Conselho Consultivo e à Comissão Organizadora da
Conferência (que reúne 41 entidades). Os documentos resultantes foram submetidos a uma consulta pública através da Internet e de um suplemento especial da Folha Dirigida, em uma edição com 300 mil exemplares, distribuída em todo o território nacional.

A primeira conferência dessa série, ocorrida em 1985, teve um papel estruturante do sistema nacional de ciência e tecnologia: nela foram debatidas não apenas estratégias para o desenvolvimento científico e tecnológico do país, mas também a estrutura das agências de financiamento. Ela foi seguida por duas outras conferências, a de 2001 , que consolidou a iniciativa de fundos setoriais introduzida em 1999, e a de 2005, cujos resultados influenciaram o Plano de Ação de Ciência, Tecnologia e Inovação para o período 2007-10.

\section{$4^{A}$ CNCTI: UMA AGENDA DE LONGO PRAZO PARA O PAÍS}

A 4a CNCTI propôs como objetivo estratégico para o país um desenvolvimento científico e tecnológico inovador, calcado em uma política de redução de desigualdades regionais e sociais, de exploração sustentável das riquezas do território nacional e de fortalecimento da indústria, agregando valor à produção e à exportação através da inovação e reforçando o protagonismo internacional em ciência e tecnologia.

Esse objetivo pressupõe a adoção de uma agenda de longo prazo, claramente delineada pela $4^{\text {a }}$ CNCTI, que inclua: a consolidação do Sistema Nacional de Ciência, Tecnologia e Inovação, reforçando a coordenação entre os diversos setores envolvidos e revendo marcos legais que ainda prejudicam a pesquisa e o desenvolvimento tecnológico, nas empresas e nas instituições de ensino pesquisa; o estímulo à inovação nas empresas, de modo que elas possam competir globalmente com produtos de alto valor agregado; o apoio da ciência e da tecnologia para a inclusão social, incentivando a difusão do conhecimento científico 
e a inovação nessa área; o uso sustentável dos biomas nacionais, incluindo o mar e o oceano; um projeto de desenvolvimento para a região amazônica, que valorize a biodiversidade e impeça a destruição da floresta; a realização de projetos de grande envergadura que promovam a autossuficiência nacional nas áreas de energia, comunicações e atividades espaciais; o domínio das tecnologias de microeletrônica, de produção de fármacos, de nanotecnologia, biotecnologia e de um conjunto de tecnologias verdes; a melhoria da qualidade da educação em todos os níveis; o aumento substancial na formação de profissionais qualificados nos níveis médio e superior; o aumento do número de pesquisadores nas empresas, nas universidades e institutos de pesquisa; a intensificação de programas destinados a reduzir o desequilíbrio regional nas atividades de ciência e tecnologia.

Uma agenda necessária e ambiciosa, que ganha destaque no Livro Azul, lançado em 27 de dezembro de 2010, e que só pode ser concretizada através de uma política de Estado que garanta a continuidade de um projeto de desenvolvimento sustentável ancorado na ciência, na tecnologia e na inovação.

\section{BENEFÍCIOS DE UMA POLÍTICA DE ESTADO}

O Brasil já experimentou os benefícios de uma política de longo prazo, a de formação de recursos humanos. Começou tarde esse processo: enquanto a Universidade de Bolonha foi fundada em 1088 e a de Harvard, em 1636, as primeiras universidades brasileiras datam do século XX. Com as proibições de impressão de livros (1747) e de estabelecimento de manufaturas (1785), impostas por Portugal, apenas no alvorecer do século XX foram fundados os institutos Oswaldo Cruz e Butantan, bem como o Instituto Agronômico de Campinas e a Escola Superior de Agricultura Luiz de Queiroz. E foi necessário esperar até 1951 para que fossem fundados o CNPq e a Capes. Mas essas iniciativas, ainda que tardias, foram fundamentais para que, na década de 1970, pudesse existir uma Embrapa, para que a Petrobrás pudesse usufruir de engenheiros de várias especialidades, geólogos, quími$\cos$, físicos, matemáticos, que ajudaram a estabelecer a sua liderança tecnológica internacional. Sem o Instituto Tecnológico da Aeronáutica,fundado em 1950,não existiria a Embraer, que coloca aviões como itens importantes de nossa pauta de exportações.

Foram fundamentais também, para o estabelecimento de uma política mais consistente e duradoura para o setor, a criação da Financiadora de Estudos e Projetos (Finep) em 1967, do Fundo Nacional de Desenvolvimento Científico e Tecnológico, em 1971, e do Ministério da Ciência e Tecnologia (MCT), em 1985.

Mais recentemente, instrumentos importantes e originais contribuíram para um aumento dos recursos para ciência, tecnologia e inovação e para o aprimoramento do arcabouço institucional: fundos setoriais, criados em 1999, que constituem hoje uma poderosa fonte de recursos para a pesquisa científica e tecnológica; a Lei de Inovação, de 2004, e a Lei do Bem, de 2005, que propiciaram incentivos ao processo de inovação nas empresas e facilitaram a colaboração entre estas e pesquisadores em universidades e institutos de pesquisa. Além disso, o Plano de Ação em Ciência, Tecnologia e Inovação (PACTI) para o período 2007-10 incluiu a inovação como um dos eixos da política governamental. Consistentemente com esse objetivo, a política industrial, lançada em 2008 com o nome de Política de Desenvolvimento Produtivo (PDP), foi voltada para investimentos em inovação, complementando a Política Industrial, Tecnológica e de Comércio Exterior (PICTE), lançada em 2004.

Atividades coordenadas entre o MCT, o CNPqe as Fundações de Amparo à Pesquisa, como o Programa de Núcleos de Excelência (Pronex) e os Institutos Nacionais de Ciência e Tecnologia, fortaleceram o sistema estadual, um fator importante para o desenvolvimento científico e tecnológico. 
No âmbito da educação, expandiu-se o sistema federal, interiorizando as universidades e criando uma rede de institutos federais de educação, ciência e tecnologia (IFETs). Fortaleceu-se também a pós-graduação, levando a uma produção científica cujo fator de impacto médio definido em termos do número de citações por artigo - está acima dos demais países do Bric (Brasil, Rússia, Índia e China). A atuação da Capes na educação básica, através do Programa Nacional de Formação de Professores e de um sistema de bolsas para essa área, foi também uma novidade importante, complementada pelo piso salarial nacional para professores da educação básica, proposto pelo MEC e aprovado pelo Congresso Nacional em 2008.

Essas conquistas têm contribuído para colocar o país em um novo patamar, que desperta o interesse internacional e permite enxergar com mais clareza os projetos e os desafios da próxima década. Demonstram também a importância de políticas consistentes e continuadas para o desenvolvimento nacional.

Podemos vislumbrar agora instituições de ensino e pesquisa que estejam entre as melhores do mundo, com a importação de cérebros de outros países, com empresas que possam competir globalmente com produtos de alto valor agregado, com a aplicação da ciência e da tecnologia para o uso sustentável de nossos biomas.

Persistem no entanto grandes desafios, o maior deles sendo a inclusão social. Trata-se de importar, para o desenvolvimento científico e tecnológico do país, os milhões de cérebros desperdiçados nas comunidades dos morros, dos mangues e da periferia das grandes cidades, de estimular os jovens espalhados por esse imenso Brasil para que participem e sejam agentes desse processo de desenvolvimento. Trata-se de usufruir plenamente da riqueza representada pelo tamanho de nossa população, por nossa extensão territorial, pela nossa diversidade regional e cultural. Essa é a condição sine qua non para um desenvolvimento sustentável.

Fruto de uma construção coletiva e do entusiasmo de milhares de brasileiros, a
4- CNTI foi um marco importante para a afirmação de uma política de Estado para a ciência e a tecnologia no Brasil. No entanto, o impacto futuro da $4^{a}$ CNTI e a influência de suas propostas na consolidação de uma política de longo prazo dependerão, em grande medida, da continuidade da grande articulação motivada pela Conferência Nacional e da possibilidade de sensibilizar a sociedade brasileira quanto à importância dos temas discutidos na conferência.

Este artigo, baseado no Livro Azul, procura sintetizar propostas da Conferência relativas a alguns dos grandes temas nela abordados: a inovação nas empresas, as tecnologias estratégicas para o desenvolvimento nacional, a ciência básica e a produção de conhecimento, a consolidação do sistema nacional de CT\&I, os biomas nacionais, a região amazônica, o uso da CT\&I no desenvolvimento social, a melhoria da educação.

\section{INOVAÇÃO NAS EMPRESAS:}

\section{BRASIL DEVE AGREGAR VALOR À SUA PRODUÇÃO E ÀS SUAS EXPORTAÇÕES}

O percentual em relação ao PIB de investimentos em P\&D no Brasil é ainda reduzido, embora o gráfico exibido na Figura 1 mostre um aumento consistente desse percentual desde 2004, quando entraram em vigor novos mecanismos de incentivo, como a Lei de Inovação e a Lei do Bem. Chegamos a 1,24\% do PIB em 2009. O percentual correspondente da Coreia era de 3,37\% em 2008; no mesmo ano, os Estados Unidos investiam 2,77\% de seu PIB em P\&D; o Japão, 3,42\%, e a China, $1,54 \%$.

$\mathrm{O}$ aumento desse percentual requer o fortalecimento de P\&D nas empresas, e depende obviamente da agenda macroeconômica, envolvendo a política industrial, mas também o câmbio e a taxa de juros 
real. A política de inovação deve ser parte de robusta política econômica e industrial, que busque mudar a estrutura industrial e abrigar mecanismos de apoio e fomento à inovação, especialmente nas empresas nacionais. Alguns aspectos merecem atenção especial: a formação de profissionais qualificados nos níveis médio e superior, o desenvolvimento do espírito empreendedor, o aprimoramento da gestão da inovação, a interação das empresas com os resultados da pesquisa científica e tecnológica, a revisão de marcos legais que dificultam a pesquisa e o desenvolvimento tecnológico.

Vários índices apontam as deficiências ainda presentes, e os desafios a enfrentarnessa área. Cerca de $39 \%$ dos pesquisadores em empresas na Coreia possuem mestrado ou doutorado (6\% doutorado e $33 \%$ mestrado). No Brasil, apenas 15\%. Na China, 35\% dos graduados são engenheiros, correspondendo a 600 mil engenheiros por ano (o que, na China, inclui profissionais formados em cursos de dois a três anos). Na Coreia do
Sul, de 25 a $30 \%$. No Brasil, apenas 6\%, correspondendo a 48 mil engenheiros por ano (dados de 2008).

O país precisa de mais engenheiros para os grandes projetos que se anunciam, mas o número de formados é pequeno, há um grande número de vagas ociosas e a evasão nos cursos de engenharia é enorme (ver Figura 2 na próxima página). Não se trata portanto apenas de aumentar as vagas para o setor, mas de reestruturar os cursos, de modo a atrair bons alunos e transformá-los em profissionais com formação ampla e sólida, evitando-se a especialização prematura, de modo que eles sejam capazes de responder às diversificadas demandas do mundo contemporâneo, em constante e rápida mutação. Os programas devem ser reavaliados e enxugados: a carga horária total para formar um engenheiro no Brasil é, em média, o dobro da carga horária no Massachusetts Institute of Technology, uma evidência da sobrecarga de aulas nos cursos oferecidos no Brasil.

\section{FIGURA $1 *$}

\section{Dispêndio nacional em pesquisa e desenvolvomento [P\&D] em relação ao produto interno bruto [PIB] por setor, 2000-09}

Por motivos editoriais, em função das necessidades de alguns textos, em várias figuras e gráficos apresentados neste dossiê foi mantida sua forma original.

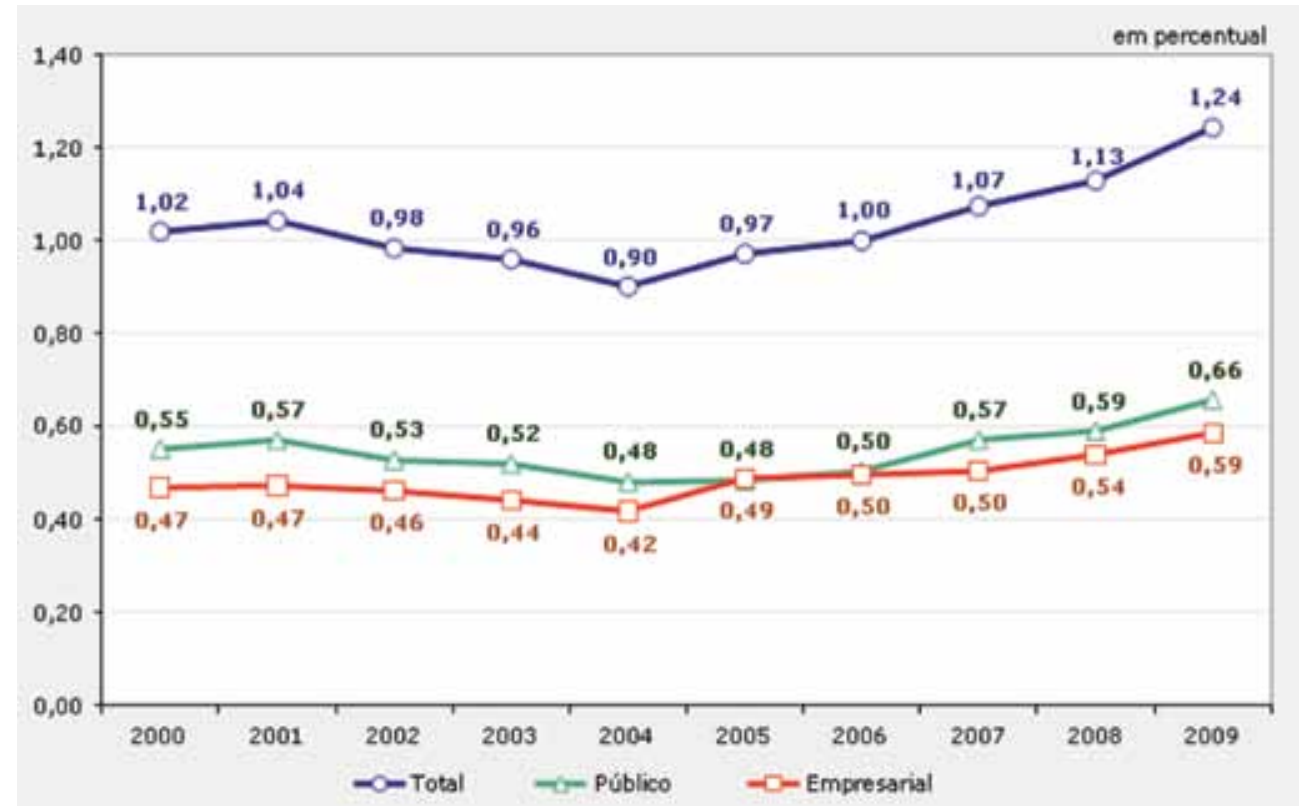

Fonte: Indicadores Nacionais de C\&T, MCT 
FIGURA 2

Vayas oferecidas no vestibular, número de ingressos e de concluintes em cursos de engenharia no país

\begin{tabular}{|c|c|c|c|}
\hline & \multicolumn{3}{|c|}{ Vestibular } \\
\hline & Vagas oferecidas & Ingressos & Concluintes \\
\hline $\mathbf{2 0 0 5}$ & 148.080 & 89.030 & 36.918 \\
\hline $\mathbf{2 0 0 8}$ & 239.134 & 140.878 & 47.098 \\
\hline
\end{tabular}

Fonte: Censo Inep (Instituto Nacional de Estudos e Pesquisas Educacionais Anísio Teixeira)

Entre as propostas apresentadas na $4^{\text {a }}$ CNCTI, destacam-se:

- Reexaminar a Lei de Inovação quanto à segurança jurídica e as contradições legais existentes, gerando subsídios para uma reestruturação dos marcos legais na área de CT\&I, tanto para os segmentos públicos como para os privados, de modo que os órgãos de fiscalização governamentais e agências de fomento atuem de forma alinhada com a política nacional na área de CT\&I.

- Fomentar maior protagonismo privado no processo de inovação e nas discussões relativas às políticas públicas para a área; estabelecer novas linhas de fomento, com critérios mais abrangentes de inovação (inovação em marketing, em serviços, em modelos e gestão de negócios, plantas piloto, plantas industriais pré-competitivas, etc.).

- Estimular estados e municípios a criar condições locais favoráveis para inovação por meio de incentivos tais como desoneração fiscal, tributária, impostos territoriais, impostos de serviço, demais tributos municipais e cessão de áreas.

- Utilizar o poder de compra do Estado, de modo a aumentar a demanda por inovação.

- Criar institutos tecnológicos que sejam interfaces entre universidades e empresas.

- Promover ambientes de inovação atuando em redes, com destaque para parques científicos e tecnológicos de classe mundial, atraindo investimentos privados nacionais e internacionais.
- Incrementar mecanismos de apoio às pequenas e médias empresas: em particular, fomentar programas de ação integrada entre empresas-âncora e suas cadeias produtivas, fortalecendo programas de extensionismo tecnológico.

- Estabelecer uma prática de negociação com empresas nacionais e multinacionais envolvendo a criação de laboratórios de P\&D.

- Dar tratamento especial às regiões menos desenvolvidas do país, com foco na redução das assimetrias intra e inter-regionais, tanto no estímulo às empresas como no desenvolvimento de competências para a produção e difusão de conhecimentos.

- Ampliaro investimento nacional em P\&D e inovação para a faixa de 2 a $2,5 \%$ do PIB em 2020.

\section{TECNOLOGIAS ESTRATÉGICAS}

\section{PARA 0 DESENVOLVIMENTO}

\section{NACIONAL}

Como consequência natural do aumento da população mundial e do desejo de uma grande parcela dessa população de melhorar o padrão de vida, pode-se prever um crescimento da produção industrial, a expansão da agricultura, o aumento da demanda por água, energia e matéria-prima, além de uma urbanização crescente, em parte não 
planejada, implicando uma grande pressão sobre a capacidade ambiental de cada região.

Nesse cenário, o Brasil tem uma posição privilegiada: possui uma das matrizes energéticas mais limpas do mundo, vantagens comparativas quanto a fontes alternativas, vastas extensões territoriais para a agricultura, e recursos naturais importantes, que oferecem uma oportunidade ímpar para uma utilização sustentável, como a Amazônia e o mar.

A 4a CNCTI enfatizou a importância da contribuição de diversas áreas da CT\&I para a construção de um novo padrão de desenvolvimento sustentável, que compatibilize o progresso material da maioria da população com o uso racional dos recursos naturais e a preservação do meio ambiente. Receberam destaque especial a agricultura, a bioenergia, as tecnologias da informação e comunicação, a saúde, a exploração das reservas de petróleo e gás do Pré-Sal, a tecnologia nuclear, as atividades espaciais, e outras tecnologias portadoras de futuro.

Entre as recomendações apresentadas, destacam-se:

- Fortalecer o Sistema Nacional de Pesquisa Agropecuária e as políticas de CT\&I e agrícola com vistas a avançar na sustentabilidade da agricultura brasileira, desenvolvendo, aperfeiçoandoe difundindo de forma ampla tecnologias eficientes de produção que conservem o solo, usem de forma eficiente a água, sejam compatíveis com a preservação do meio ambiente e da biodiversidade, e que permitam o aumento da produção sem expansão significativa da área ocupada.

- Consolidar a liderança mundial do país na área de biocombustíveis durante a próxima década, adotando para isso - em estreita articulação com o setor empresarial nacional - um vigoroso programa de pesquisa, desenvolvimento, inovação e difusão de tecnologias voltado para a produção e o uso de bioenergias.

- Ampliar de forma significativa os esforços que vêm sendo realizados na área das tecnologias de informação e comunicação (TIC), fortalecendo a pesquisa e o desenvolvimento e a formação de recursos humanos nessa área, integrando o país com uma infraestrutura de comunicações de alta velocidade, e avançando no processo de universalização do acesso à Internet.

- Avançar na abordagem sistêmica da área de saúde, articulando a política de CT\&I com a de saúde propriamente dita e com a política industrial. Em particular, utilizar o poder de compra do Estado para maximizar seus resultados no médio e longo prazo e não simplesmente para minimizar os custos imediatos; aperfeiçoar e compatibilizar os regimes normativos da área (especialmente a vigilância sanitária, o acesso à biodiversidade e o intercâmbio de material biológico) e fortalecer a capacidade de realização de testes clínicos no Brasil.

- Associar à exploração do Pré-Sal o fortalecimento da cadeia de fornecedores locais, a consolidação de empresas brasileiras como competidores globais, a agregação de valor aos seus produtos e a geração de empregos qualificados no país.

- Aperfeiçoare aumentar a escala dos atuais programas de promoção de energias fotovoltaica e eólica, utilização do hidrogênio em células combustíveis e energia nuclear, fundamentais para que o país se torne um ator relevante nesses setores, que serão vitais para a sociedade do futuro.

- Avançar na consolidação do domínio do ciclo completo do combustível nuclear, aumentar a produção de radiofármacos, desenvolver aplicações nucleares na área de propulsão e capacitar o país na construção e operação de depósitos de rejeitos radioativos.

$\mathrm{Na}$ área espacial, desenvolver a capacidade nacional de projetar, fabricar, lançar e operar satélites.

\section{MOMENTO HISTÓRICO PARA 0 AVANÇO DA CIÊNCIA BRASILEIRA}

O avanço da ciência no Brasil tem sido notável nas últimas décadas, tanto qualitativa como quantitativamente. $O$ crescimento 
do número de artigos publicados em revistas indexadas tem estado muito acima da média mundial, o que levou o Brasil a ocupar o 13을 lugar mundialmente, atingindo, em 2009, $2,69 \%$ da produção mundial. Em termos de impacto relativo médio das publicações do Brasil em cada área de conhecimento, em relação às respectivas médias mundiais, $o$ país estava em 2009 à frente dos demais países do chamado grupo Bric (Brasil, Rússia, Índia e China), mas bastante ameaçado pela China e pela Índia (ver Figura 3 ).

Fortalece-se também a presença internacional da ciência brasileira, através da participação em influentes fóruns internacionais, como o Grupo G8+5 de Academias de Ciência, através de um número crescente de colaborações internacionais, e da forte presença no exterior de empresas e instituições brasileiras como a Embrapa, a Petrobras e a Fiocruz.

Apesar desses sucessos, o país tem ainda grandes desafios a enfrentar. O número de doutores por 100 mil habitantes $(4,6)$ é ainda 1/3 do número correspondente na Coreia e, como mencionado anteriormente, é modesto o investimento em P\&D nas empresas. As instituições de ensino e pesquisa nacionais aparecem apenas marginalmente nas listas de melhores do mundo. O intercâmbio internacional precisa ser incrementado para que passemos a um novo patamar, substituindo o brain drain pelo brain gain. A educação superior precisa ser reestruturada, adaptando-se às exigências do mundo contemporâneo.

Tomando como marco temporal o ano de 2020, é preciso alcançar avanços sig-

\section{FIGURA 3}

\section{Fator de impacto médio dos países do grupo Bric [Brasil, Rússia, Índia e China]}

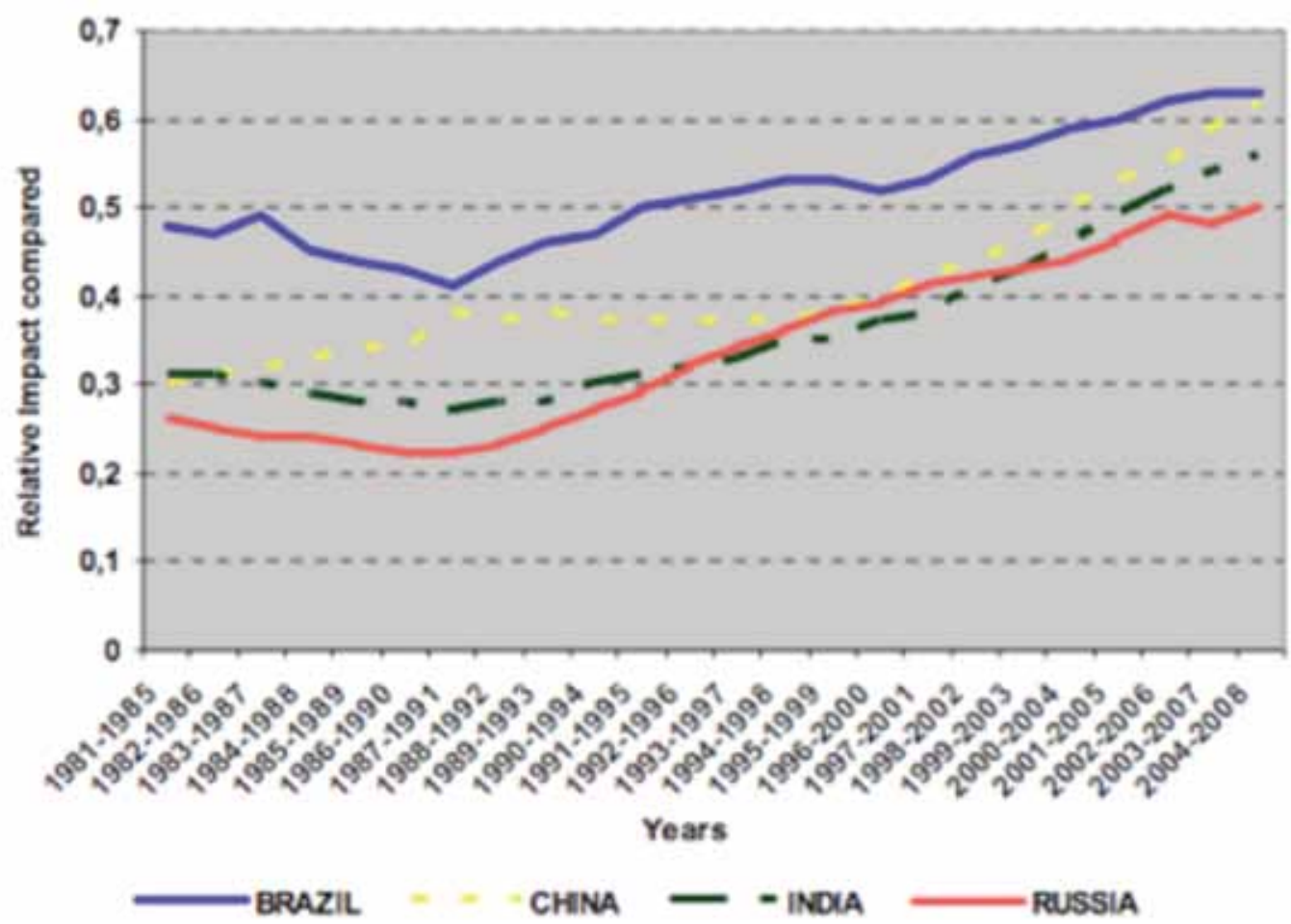

Fonte:Thomson Reuters National Science Indicators 
nificativos na titulação anual de mestres e doutores, com a devida prioridade na concessão de bolsas de estudos nas áreas consideradas mais estratégicas e/ou carentes no país, como, por exemplo, engenharias, oceanografia, biologia marinha e matemática; no contingente de pesquisadores e técnicos da área de CT\&I no país, inclusive investimentos no treinamento de analistas e técnicos de laboratórios; na produção de trabalhos científicos em revistas qualificadas; em investimentos nas atividades de cooperação científica internacional; em investimentos em infraestrutura, com a expansão do sistema universitário, institutos de pesquisa e laboratórios, inclusive de grande porte.

Além dessas, destacam-se ainda como recomendações:

- Aperfeiçoar os mecanismos de absorção de cientistas estrangeiros qualificados. Em particular, os concursos para professores e pesquisadores de universidades e institutos de pesquisa devem ter caráter mundial, admitindo-se o uso de língua estrangeira de uso bastante universal, como o inglês, desde que os participantes se comprometam a aprender a língua portuguesa em até dois anos após o concurso.

- Promover a autonomia das instituições de excelência de C\&T na constituição de seus quadros de pesquisadores e técnicos, valorizando a ciência fundamental nelas desenvolvida e provendo-as de adequado apoio.

- Aperfeiçoar mecanismos de formação e fixação de cientistas nas regiões do país que mais carecem de sólida competência em ciência e tecnologia, provendo a infraestrutura necessária.

- Promover programa especial, em bases competitivas, para apoiar planos de excelência das instituições de pesquisa e universidades com o objetivo de situá-las entre as melhores do mundo.

- Promover modalidades de apoio a pesquisas com duração de até cinco anos para projetos de natureza mais ousada e/ou abrangente.
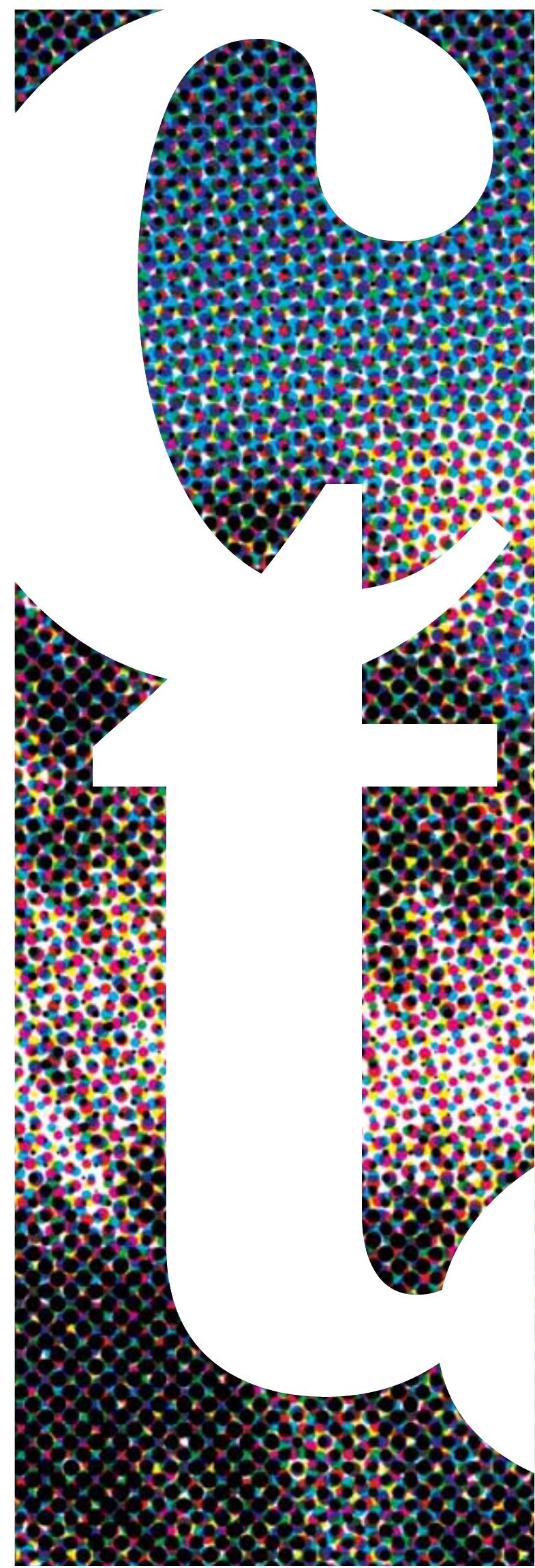
pelo presidente da República, e que poderia ter uma função de Estado. Para cumprir de forma adequada sua missão e desempenhar com eficiência papel de articulação, além de atuar como instrumento de coordenação central do sistema nacional de CT\&I, o CCT carece de aprimoramento em sua estrutura e funcionalidade. Os principais desafios consistiriam em melhorar a representatividade dos diferentes atores no conselho, na capacidade de gerar novas ideias e no poder real de influenciar as políticas.

\section{OS GRANDES DESAFIOS E A AGENDA DO FUTURO}

A redução das desigualdades regionais e sociais, o uso sustentável dos biomas nacionais, um "choque de inteligência" na Amazônia, agregando valor à biodiversidade e valorizando a "floresta em pé", a melhoria da qualidade da educação em todos os níveis são os grandes desafios apontados na $4^{\mathrm{a}} \mathrm{CNCTI}$.

Um dos grandes desafios para o Brasil é a utilização sustentável do patrimônio nacional constituído por sua biodiversidade. Maior do planeta, a biodiversidade brasileira tem enorme valor estratégico com importância equivalente ao Pré-Sal. E a CT\&I oferece meios para a valorização e a utilização não predatória da natureza.

Enfatizou-se, na $4^{\text {a }}$ CNCTI, a necessidade de atualizar o marco legal de acesso à biodiversidade.Hoje, as dificuldades legais impedem o trabalho dos pesquisadores e das instituições nacionais. A limitação no uso de material biológico bem como a dificuldade de permuta de material genético têm retardado os projetos de pesquisa e acentuado a pirataria.

Por outro lado, graças em grande parte à pesquisa e desenvolvimento na área de agricultura, o país multiplicou por quatro o valor de suas exportações agrícolas entre 2000 e 2008, já é o terceiro maior exportador de alimentos e pode alcançar o segundo lugar nos próximos dez anos. É também o segundo produtor e o maior exportador mundial de etanol.

Projeta-se que em duas décadas aproximadamente $60 \%$ do consumo de energia do país seja proveniente de fontes renováveis, o que distinguirá o Brasil de qualquer outra nação, colocando-o em posição de destaque do ponto de vista sustentável.

Cumpre promover também ouso sustentável dos recursos naturais do mar. Trata-se de uma extensão atlântica que se projeta para além do litoral e das ilhas oceânicas, repleta de riquezas minerais e biológicas espalhadas por mais de 4,5 milhões de quilômetros quadrados, também conhecida como “Amazônia Azul”. São questões importantes: porque os ecossistemas marinhos estão mudando? Em que escala precisamos preservar a biodiversidade marinha?

Entre todas as regiões, a Amazônia emergiu na 4 ${ }^{\mathrm{a}}$ CNCTI como o grande desafio, um ponto central em uma agenda do futuro, pela sua extensão territorial (a Amazônia legal corresponde a 59\% do território nacional), pela riqueza que encerra, e pelas repercussões internacionais. A agenda de CT\&I para essa região é diversificada e complexa, envolvendo o aproveitamento sustentável dos recursos minerais e da biodiversidade, o aproveitamento da água e sua conservação.

Entre as várias recomendações para essa região, destacam-se:

- Criar uma coordenação supraministerial para articular instituições que lidam com biodiversidade, com inclusão do Centro de Biotecnologia da Amazônia (CBA), para promover a produção de fitomedicamentos e fármacos.

- Estabelecer mecanismos que atraiam empresas de base tecnológica voltadas para a biodiversidade com financiamentos diferenciados.

- Criar uma plataforma tecnológica para uso, manejo e preservação da água na Amazônia brasileira e promover sua articulação no âmbito da Bacia Amazônica.

- Desburocratizar e facilitar o acesso dos pesquisadores brasileiros à pesquisa da biodiversidade. 
- Estabelecer um programa de educação técnica, profissionalizante e universitária articulado a empreendimentos dirigidos para o desenvolvimento econômico e humano da Região Amazônica.

- Avançar no conhecimento científico da Amazônia, implicando pesquisas e viabilização de novas potencialidades regionais, tais como serviços ambientais e energia solar.

- Aperfeiçoar o programa aeroespacial brasileiro para monitoramento socioambiental da Amazônia com base em satélite nacional e compartilhá-lo com os demais países amazônicos.

\section{CT\&I PARA 0 DESENVOLVIMENTO SOCIAL}

O uso da CT\&I para o desenvolvimento social teve um espaço importante na $4^{\text {a }}$ CNCTI. É ainda um dos grandes desafios e um tema central na agenda de desenvolvimento científico e tecnológico. Nos últimos anos, avançou-se na popularização da ciência e no apoio à inovação social, mas há ainda um complexo caminho a percorrer.

O mercado não é o único motor de inovação. Muitas inovações que transformaram o mundo surgiram de instituições públicas ou de setores sem fins lucrativos; a Internet é um exemplo recente. No Brasil, o desenvolvimento dessa área requer o apoio à pesquisa, à produção e ao uso de tecnologias sociais inovadoras, inclusivas e participativas. Também é preciso que se introduza a inovação social no setor público, em particular em modelos de gestão e organização, possibilitando além disso a apropriação da C\&T pelas comunidades locais.

Em particular, a extensão universitária é uma atividade essencial para que a universidade forme não apenas profissionais qualificados e inovadores, mas também cidadãos comprometidos com a sociedade em que vivem e esclarecidos em relação a políticas públicas que cada vez mais envol- vem complexas questões científicas, como a exploração sustentável da biodiversidade, as opções energéticas do país, o uso de células-tronco.

Uma ideia que teve grande aceitação é a criação de um fundo setorial para atividades de inovação social e tecnologia social, com recursos do sistema financeiro.

As diversas recomendações relativas ao desenvolvimento social detalham os seguintes grandes temas:

- Estabelecimento e execução do Programa Nacional de Popularização e Apropriação Social da CT\&I 2011-2022, envolvendo universidades e instituições de pesquisa, organismos governamentais e da sociedade civil.

- Formulação e implantação de um Programa Nacional de Inovação e Tecnologia Social, com apoio a pesquisas e projetos, promovendo o envolvimento da sociedade civil organizada na sua elaboração, execução, monitoramento e avaliação.

- Estabelecimento de políticas e programas específicos para a difusão, apropriaçãoe uso da CT\&I para o desenvolvimento locale regional e para estimular empreendimentos solidários.

- Estabelecimento de políticas públicas de CT\&I voltadas para a democratização e a cidadania, com ênfase em ações para a inclusão digital.

- Formulação e execução de uma política pública e programas nacionais para a recuperação, preservação, valorização e acesso público ao patrimônio científico, tecnológico e cultural brasileiro.

\section{O BRASIL PRECISA DE UMA REVOLUÇÃO NA EDUCAÇÃO}

Nos meses que antecederam a Conferência Nacional, e durante o período de sua realização, nenhum tema foi tão debatido pelos mais diversos setores da sociedade quanto a necessidade imperiosa de melhorar a qualidade da educação. 
Esse objetivo não será alcançado com melhorias incrementais: é necessário uma política ousada, que envolva o país como um todo, nos níveis federal, estadual e municipal, para atacar um problema aguçado por décadas de negligência.

A baixa escolaridade da população brasileira constitui importante obstáculo ao desenvolvimento científico e tecnológico do país. A Figura 4 mostra, através da comparação donível de instrução entre duas faixas etárias, como a fração da população com nível superior aumentou muito pouco ao longo das últimas décadas se comparada com a evolução de outros países.

Os grandes projetos previstos para a próxima década, nas áreas de petróleo, bio- energias, saúde, tecnologias de informação e comunicação, exploração sustentável dos biomas, entre outros, requerem um grande número de profissionais bem qualificados nos níveis técnico e superior. E a formação desse contingente pressupõe uma educação básica de qualidade para todos os brasileiros.

Não obstante o progresso da pós-graduação no Brasil, graças a uma verdadeira política de Estado ao longo de décadas, a graduação apresenta um perfil arcaico na maioria das universidades brasileiras, e é dominada ainda por instituições privadas de baixa qualidade. Experiências recentes de modernização, como a da Universidade Federal doABC, ajudam a mudar esse panorama, mas são ainda restritas a poucas ins-

FIGURA 4

Percentual da população com nível superior, por faixa etária

Chart A1.3. Population that has attained at least tertiary education (2006) Percentage, by age group

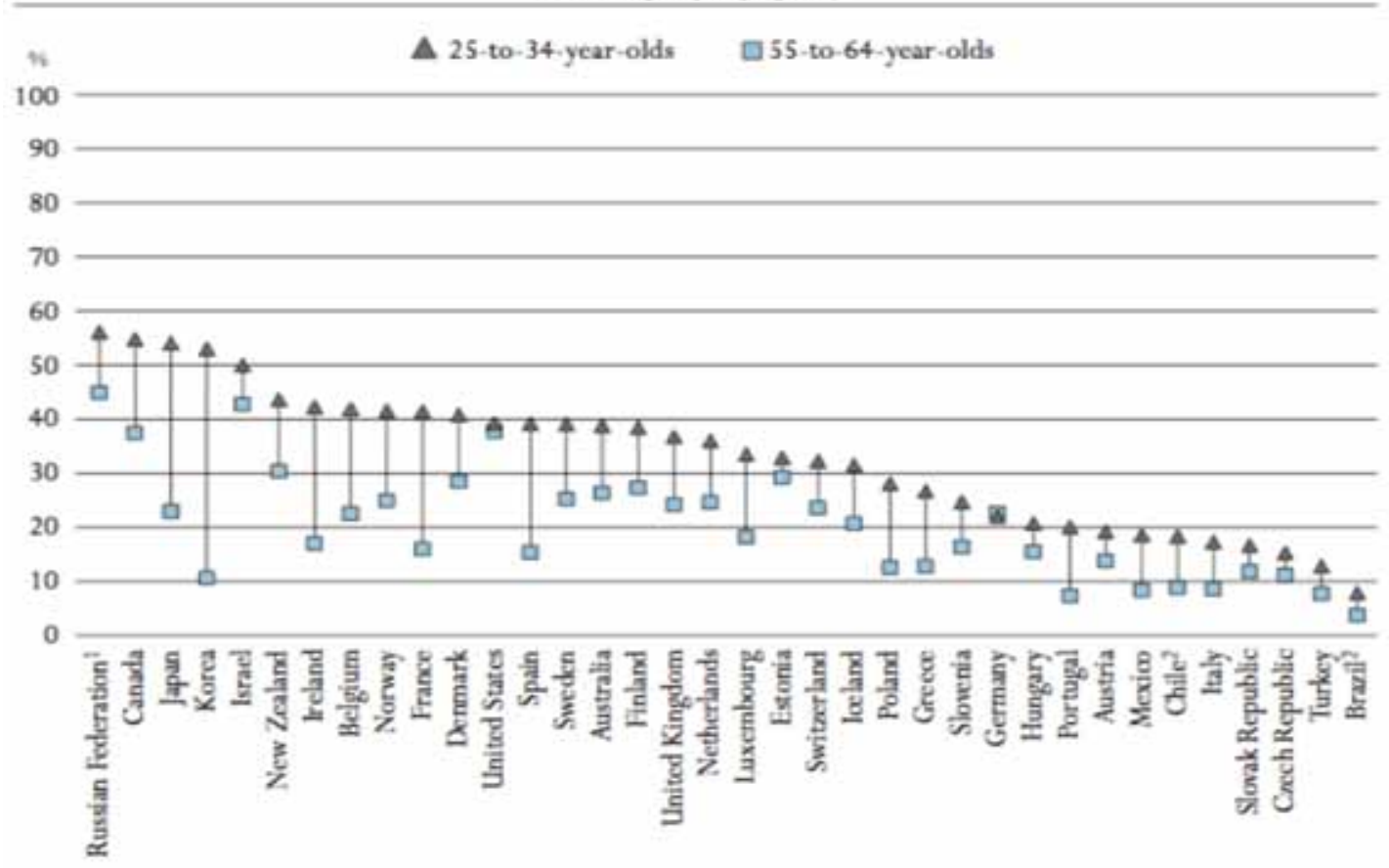

1. Year of reference 2002.

2. Year of reference 2004 . 
tituições. E a diversificação de instituições de ensino superior, modelo bem-sucedido que, em outros países, ajudou a aumentar substancialmente o número de estudantes no nível superior, enfrenta ainda resistências dentro da comunidade acadêmica.

Mas o grande desafio está no ensino básico, que demanda um projeto de grande envergadura, tendo como ponto central a valorização do professor desse nível de ensino, com salário inicial atraente, comparável ao de outras profissões graduadas, e carreira motivadora, com oportunidades de formação continuada e especialização. Em particular, o piso salarial nacional deve ser progressivamente aumentado, de modo a atingir valores que atraiam bons estudantes para essa profissão. Aexperiência de outros países mostra que a valorização do professor influencia rapidamente a qualidade dos estudantes que decidem se dedicar a essa profissão. Na Coreia, por exemplo, o vestibular para candidatos a professor de educação fundamental é extremamente concorrido, com dez candidatos para cada vaga. Os alunos selecionados estão entre os 5\% melhores estudantes do secundário.

Propôs-se ainda, no âmbito da educação básica, a implantação do turno integral na escola pública, privilegiando não só a educação formal, mas também a socialização da criança, por meio de atividades de educação física e artísticas, clubes de ciência e leitura. O turno escolar para a educação básica deve ser de no mínimo seis horas e atingir oito horas para a educação fundamental em comunidades carentes. Recomenda-se, além disso, expandir a educação infantil, o que comprovadamente reduz o fracasso escolar.

Esse conjunto de iniciativas, por si só, requer um aumento substancial dos gastos com a educação básica. Por isso mesmo, a proposta da Conferência Nacional de Educação, de que em 2020 os gastos com a educação cheguem a $10 \%$ do PIB, foi endossada pela $4^{\text {a }}$ CNCTI.

A 4 ${ }^{\text {a }}$ CNCTI enfatizou ainda a importância de um ensino adequado de ciências, propondo a incorporação à escola e aos programas de formação de professores da educação em ciências baseada na investigação, incentivando a produção de materiais e metodologias inovadoras. Na escola, a criança deve aprender a ler, a contar e a experimentar.

O desenvolvimento científico e tecnológico do país requer, por outro lado, a ampliação da educação pública de nível superior, com diversificação institucional e flexibilidade curricular, incentivando-se diversos percursos formativos, de modo a garantir a formação de profissionais com perfil adequado. A criação recente de novos campi e novas universidades e institutos de tecnologia e a ampliação de vagas promovida pelo programa Reuni aumentaram o percentual de jovens entre 18 e 24 anos matriculados em instituições de educação superior no país, de $9 \%$, em 2004 , para cerca de $14,4 \%$, em 2009. Mas esse percentual é ainda muito baixo comparado com o de países da OCDE (60\% nos Estados Unidos) e mesmo da América Latina (30\% na Argentina). Em vários países da OCDE, o aumento da população de nível superior foi conseguido graças à diversificação de modelos, incluindo não apenas universidades, mas institutos tecnológicos e outras instituições com cursos de dois a três anos, voltados para uma formação mais geral.

A 4ํㅡㄴ CNTI, de olho no futuro, deixa uma importante mensagem, repetida em diversas sessões da conferência: o Brasil, em virtude do momento histórico em que vive, das características de seu território, de sua matriz energética, de sua diversidade regional e cultural, do tamanho de sua população, e do patamar científico que já alcançou, tem uma oportunidade única de construir um novo modelo de desenvolvimento sustentável, que respeite a natureza e os seres humanos. Um modelo que necessariamente deverá se apoiar na ciência, na tecnologia e na educação de qualidade para todos os brasileiros. 